\title{
Mushroom thrombus" A unique post transcatheter mitral valve replacement (Valve in valve) early complication
}

\author{
Hemant Chaturvedi ${ }^{1}$ and Ravinder Rao $^{2}$ \\ ${ }^{1}$ Eternal Hospital and Research Institute \\ ${ }^{2}$ Eternal Heart Care Center
}

November 27, 2020

\begin{abstract}
The incidence of prosthetic valve thrombosis post transcatheter mitral valve replacement remains largely unknown. Although it may occur more frequently than after transcatheter aortic valve replacement, only isolated cases have been reported up to now. This unique large mushroom thrombus post TMVR case is first of its kind reported ever. 3D transesophageal as well as transthoracic echocardiography play very important role in early diagnosis and for treatment decision
\end{abstract}

Title:" Mushroom thrombus" A unique post transcatheter mitral valve replacement (Valve in valve) early complication

\section{Authors details: Corresponding and first author}

Dr. Hemant Chaturvedi (First and corresponding author):

MBBS, Diploma Cardiology, FACC

Head, Department of Noninvasive cardiology, Eternal hospital, Jaipur (Rajasthan) 302017

Email ID: drhemant.chaturvedi@gmail.com

Address of correspondence :

Dr. Hemant Chaturvedi

Head, Department of Noninvasive cardiology,

Eternal hospital, 3A, Jagatpura road

Jawahar circle, Jaipur (Rajasthan) 302017

Ph: +919784236879

Email ID: drhemant.chaturvedi@gmail.com

Second Author:

Dr Ravinder singh Rao, MD, DM, FACC

Director structural heart disease, Consultant Intervention cardiology

Eternal hospital, 3A, Jagatpura road

Jawahar circle, Jaipur (Rajasthan) 302017 
Email id: drravindersinghrao@yahoo.co.in

\begin{abstract}
:
The incidence of prosthetic valve thrombosis post transcatheter mitral valve replacement remains largely unknown. Although it may occur more frequently than after transcatheter aortic valve replacement, only isolated cases have been reported up to now. This unique large mushroom thrombus post TMVR case is first of its kind reported ever. 3D transesophageal as well as transthoracic echocardiography play very important role in early diagnosis and for treatment decision.
\end{abstract}

\title{
Key words:
}

Mushroom thrombus, post TMVR, 3D TEE

\section{Case :}

A 53-year-old lady follow up case of rheumatic heart disease, post MVR; bioprosthetic valve (Epic \#25) implanted 6 years ago. She developed progressive breathlessness for last 3 months NYHA class III. Transthoracic as well as transesophageal echocardiography (TEE) suggested dysfunction prosthetic valve with flail leaflet leading to severe MR (Fig A).

Patients with contraindication or high risk for surgical treatment and failed surgical bioprosthesis or annuloplasty; Transcatheter mitral valve replacement (TMVR) is a good therapeutic option $[1,2]$

She was implanted $23 \mathrm{~mm}$ bioprosthetic Meril's My valve (valve in valve) via percutaneous transcatheter technique right femoral vein under 3D TEE guidance (Fig B). Result was satisfactory (Mean pressure gradient $3 \mathrm{mmHg}$ ) with no residual mitral regurgitation.

After 1 month follow up, she had some breathing difficulty for which transthoracic echocardiography,\& 2DTEE were done which showed a mobile hyperechogenic mass hanging over prosthetic valve (Fig C) with significant gradients across mitral inflow, mean gradients were $18 \mathrm{mmHg}$ (Fig D) 3D transesophageal echocardiography from left atrial side view showed a unique mushroom like mobile mass hanging over prosthetic valve, measuring $20 X 30 \mathrm{~mm}$ (fig E).

In view of significant gradients and obstruction of color flow across valve; thrombolysis was done with streptokinase bolus followed by intravenous continuous infusion. After 24 hours, echocardiography reviewed showed significant reduction in gradients (MPG $6 \mathrm{mmHg}$ ) and disappearance of mass. 3D trans thoracic echocardiography revealed normal functioning of valve with no mass as seen previously (Fig F)

On review of literature, the incidence of prosthetic valve thrombosis post TMVR remains largely unknown. Although it may occur more frequently than after transcatheter aortic valve replacement, only isolated cases have been reported up to now [3,4]. This unique large mushroom thrombus post TMVR case is first of its kind reported ever.

\section{Conclusion:}

The incidence of THV thrombosis after TMVR remains largely unknown. Until unless systemic echocardiographic follow-up is not performed, this complication may remain undiagnosed.

Mild raised trans mitral gradients on trans thoracic gradients usually overlook the post TMVR thrombus that's why systemic TEE may be necessary during follow-up of these patients and must be mandatory in patients with elevated trans mitral gradients.

Early or late subclinical prosthetic valve thrombosis may occur frequently after TMVR, and long-term anticoagulant therapy may therefore be necessary in combination with antiplatelet therapy despite the increased bleeding risk.

\section{Conflict of interest declaration:}

This is an original manuscript and has not been previously published or submitted into another journal 
Dr Hemant Chaturvedi, \& Dr. Ravinder Singh Rao declare, that they have no financial disclosure and no conflict of interest to be disclosed.

\section{References:}

1. Himbert D, Descoutures F, Brochet E, et al. Transvenous mitral valve replacement after failure of surgical ring annuloplasty. J Am Coll Cardiol 2012; 60:1205-6.

2. Himbert D, Bouleti C, Iung B, et al. Transcatheter valve replacement in patients with severe mitral valve disease and annular calcification. J Am Coll Cardiol 2014;64:2557-8.

3. Quick S, Speiser U, Strasser RH, et al. First bioprosthesis thrombosis after transcatheter mitral valve-invalve implantation: diagnosis and treatment. J Am Coll Cardiol 2014;63:e49.

4. Whisenant B, Jones K, Miller D, et al. Thrombosis following mitral and tricuspid valve-in-valve replacement. J Thorac Cardiovasc Surg 2015;149:e26-9.

\section{Hosted file}

TMVR thrombus.pptx available at https://authorea.com/users/377385/articles/495597-mushroomthrombus-a-unique-post-transcatheter-mitral-valve-replacement-valve-in-valve-earlycomplication 